\title{
Experimental proof on methane polymerization caused isotopic reversals of natural gas formed at over maturity
}

\author{
JINGKUI MI, GUOYI HU, KUN HE
}

\author{
Research Institute of Petroleum Exploration and \\ Development, PetroChina. E-mail: \\ jkmi@petrochina.com.cn
}

More and more natural gas from organic matter with over maturity was found bearing a feature of isotope reversal in recent years. Meanwhile, the depth and the maturity of source rock for natural gas become greater and higher. However, the views about isotope reversal of gas and maturity limit for natural gas exploration are still in controversy or absent experiment data to support. In this study, methane polymerization and cracking experiments were conducted to probe above problems. The experiment result shows that methane would polymerize to form heavy gas before it bulk crack. Moreover, the heavy gas by methane polymerization shares the feature of depleted carbon isotope. The reversal range of carbon isotope between methane and ethane produced by methane polymerization is consistent with that of shale gas and tight sandstone gas from source rock with over maturity. The geological deduction of experiment data proves that methane polymerization becomes obvious at the maturity level of $\mathrm{R}_{\mathrm{o}}>2.5 \%$ in which gas generation from source rock trends to exhausting. Thus, methane polymerization should be a main mechenism to cause isotope reversal of gas generated at over maturity. The data of methane cracking indicates that bulk decomposition of methane would happen at the maturity level of $R_{0}>6.0 \%$. So, it should be the highest maturity limit of $6.0 \% \mathrm{R}_{\mathrm{o}}$ to explore natural gas.

\section{References:}

[1] Burruss R C, Laughrey C D. 2010. Carbon and hydrogen isotopic reversals in deep basin gas: evidence for limits to the stability of hydrocarbons. Org. Geochem 42, $1285-1296$

[2] Tilley, B.J., Muehlenbachs, K., 2013. Isotope reversals and universal stages and trends of gas maturation in sealed, self-contained petroleum systems, Chem.Geol 339, 194-204. 